\section{Vitamin D dosing for infectious and immune disorders}

\author{
Scott T Weiss, Augusto A Litonjua
}

The most natural way that humans get vitamin D into their body is through exposure to sunlight. If one is at the equator in the summer without sunscreen, human skin will produce approximately $10000 \mathrm{IU}$ of vitamin D over one hour, a testament to the incredible reserve that human skin has to translate ultraviolet light B (UVB) exposure into vitamin D3 levels in serum.

However, modern culture has made sun exposure an inefficient transducer of vitamin D. First, humans spend upwards of $90 \%$ of their time indoors and, when outside, have clothes and sunscreen on, both of which reduce the exposure to UVB radiation and, consequently, the production of vitamin D in the skin. Finally, in countries such as the UK, that are far north of the equator, for at least 6 months of the year, there is significantly less UVB radiation that reaches the earth's surface given the larger solar zenith angle of the sun's rays with respect to the earth's surface. ${ }^{1}$ We are a long way from where modern humans originated, 10000 years ago, naked, at the equator and outdoors $100 \%$ of the time.

Thus, to get enough vitamin $\mathrm{D}$, humans must rely on supplementation of their diet to attain appropriate intake. The fact that we have this dual mechanism is testament to the critical biological role that vitamin D plays in human immunity and physiology. This dietary supplementation has been used since the middle of the 18th century when cod-liver oil was regularly used to treat rickets. Unfortunately, we have got away from cod-liver oil, and there is now considerable controversy as to how much vitamin D people should take for immune function. Things are clearer for bone health. We only need to target a serum level of $20-30 \mathrm{ng} / \mathrm{mL}$, or $50-$ $75 \mathrm{nmol} / \mathrm{L}$, to prevent rickets. Bone and Ca metabolism are clearly controlled by serum levels of vitamin D and parathyroid hormone, for example, via an endocrine feedback system. Even at these modest levels, a considerable percentage of the

Channing Division of Network Medicine, Department of Medicine, Brigham and Women's Hospital and Harvard Medical School, Boston 02115, Massachusetts, USA

Correspondence to Dr Scott T Weiss, Harvard, Boston, MA, USA, scott.weiss@channing.harvard.edu adult UK population (between $40 \%$ and $80 \%$ depending on age group) and the world's population (greater than $40 \%$ in many countries) is deficient, for example, below $20 \mathrm{ng} / \mathrm{mL}$ or $50 \mathrm{nmol} / \mathrm{L}^{2}{ }^{3}$

While the likely optimal level for bone health is known, the central question is what level is needed for prevention of infection and immune health? Here is where things get murky. There is a suggestion from an observational study by Sabetta et $a l,{ }^{4}$ where 25 OHD (25 hydroxy D) was measured monthly, that maintaining a serum level of at least $38 \mathrm{ng} / \mathrm{mL}$ is needed for adequate protection from acute respiratory infections. In addition, since most immune cells have the biochemical apparatus to make the active form of vitamin D, for example, 1,25 dihydroxy D $(1,25$ $\mathrm{OHD})$ and there is diffusion of vitamin D3 (the precursor molecule) and $25 \mathrm{OHD}$ into the tissues it is likely that the levels needed are not well reflected by the levels in the serum and that higher serum levels are required for immune health. We believe that this level should be in the range of $40-60 \mathrm{ng} / \mathrm{mL}$ or $100-150 \mathrm{nmol} / \mathrm{L}$.

What are the implications of needing this higher level for immune health? There are several. The first implication is that serum levels are a poor reflection of tissue levels and reliance on $25 \mathrm{OHD}$ levels as the sole index of normal vitamin D status is probably insufficient and misleading. ${ }^{5}$ The second implication is that while levels for bone health are well established, the levels needed for infectious and immune health are not as clear. People frequently cite the level of $30 \mathrm{ng} / \mathrm{mL}$ or $75 \mathrm{nmol} / \mathrm{L}$ as the upper range of normal for immune health but this is completely unproven. What does appear to be true is that you don't begin to get suppression of parathyroid hormone until the serum level is $40 \mathrm{ng} / \mathrm{mL}$ suggesting that this is the true lower limit of normal, not $30 \mathrm{ng} / \mathrm{mL}^{6}{ }^{6}$ Now niche populations such as the Masai in Africa and professional surfers are among the few people in the world with adequate sun exposure to get normal serum levels of vitamin D and they have levels of $40-60 \mathrm{ng} / \mathrm{mL} \quad(100-$ $150 \mathrm{nmol} / \mathrm{L})$ a range thought by many, including us, to be more appropriate for infectious and immune health than current recommendations. ${ }^{78}$ If we are correct then the level of human vitamin D deficiency is truly astounding as $99+\%$ of the world's population would be deficient and substantially so. Given these assumptions, clinical trials are critical to prove the appropriate dosing of vitamin $\mathrm{D}$; observational studies are unable to do this given the massive levels of insufficiency worldwide.

All this serves as important background in considering the recent ViDiFlu trial in this issue of Thorax. ${ }^{9}$ In this trial the investigators used a clever block randomisation scheme to attempt to prevent influenza outcomes with vitamin D supplementation. In addition to the usual daily dose of $400 \mathrm{IU}$ in the elderly they employed bolus dosing every 2 months with $2.4 \mathrm{mg}$, for example, $96000 \mathrm{IU}$. Being in the treatment group was actually associated with an increased risk of upper respiratory tract infection (URI) and increased duration of URI symptoms.

Clearly the vitamin D didn't work to reduce infections so what went wrong here? The first problem was that 25 hydroxy vitamin D levels were the only measure of treatment efficacy and the measurements were taken at 2 months and 12 months at trough times, for example, well after the last bolus dose. The mean 2-month level was 65.5 nmoles below the target level of $75 \mathrm{nmoles} / \mathrm{L}$ and certainly well below 100 nmoles/L. The 12-month level was $85.375 \mathrm{nmoles} / \mathrm{L}$ so, above 75 nmoles/L, but still well below 100 nmoles/L. So it looks as if the dosing was too low to achieve adequate tissue levels, and certainly well below the level that Sabetta et $a l^{4}$ had previously shown to be effective in preventing acute respiratory infections. In addition, as noted by the authors, the whole concept of bolus dosing of vitamin $\mathrm{D}$ is problematic. Intermittent bolus dosing with long lag times (greater than 3-4 weeks) leads to wide swings in circulating levels of $25 \mathrm{OHD}$, which in turn leads to dips in tissue levels of 1,25 dihydroxy $\mathrm{D}$, leading to a relative excess of the catabolic enzyme 24 hydroxylase. ${ }^{10}$ This mechanism has also been suggested to be operating in elevating the risk for some cancers due to wide fluctuations in circulating vitamin D levels. Given the adverse effects associated with vitamin D supplementation seen in this trial, a mechanism similar to this is likely to be operating. In support of this idea other bolus dosing trials have been null, ${ }^{11-13}$ while trials using regular oral dosing even in modest levels have been protective. ${ }^{14} 15$

In summary vitamin $\mathrm{D}$ has very complex biochemistry and in designing trials using it as a treatment modality we 
should avoid wide swings in tissue levels by infrequent bolus dosing, not rely on intermittent serum monitoring and try to attain a consistent immune protective level of $100-150 \mathrm{nmoles} / \mathrm{L} \quad(40-60 \mathrm{ng} / \mathrm{mL})$. If we do these things we will see some positive results and benefit our patients.

Contributors STW did the first draft of the editorial. AAL did the second draft and STW did the third and final draft. Both authors added references.

Funding National Heart Lung and Blood Institute (R01 HL091528).

Competing interests None declared.

Provenance and peer review Commissioned; internally peer reviewed.

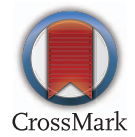

To cite Weiss ST, Litonjua AA. Thorax 2015;70:919920.

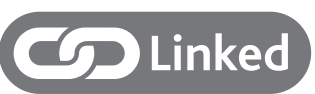

http://dx.doi.org/10.1136/thoraxjnl-2015-206996
Thorax 2015;70:919-920.

doi:10.1136/thoraxjnl-2015-207334

\section{REFERENCES}

1 Webb AR. Who, what, where and when-influences on cutaneous vitamin D synthesis. Prog Biophys Mol Biol 2006;92:17-25.

2 Lips P. Worldwide status of vitamin D nutrition. J Steroid Biochem Mol Biol 2010;121:297-300.

3 Palacios C, Gonzalez L. Is vitamin D deficiency a major global public health problem?. I Steroid Biochem Mol Biol 2014;144(Pt A):138-45.

4 Sabetta JR, DePetrillo P, Cipriani RJ, et al. Serum 25-hydroxyvitamin $d$ and the incidence of acute viral respiratory tract infections in healthy adults. PLOS ONE 2010;5:e11088.

5 Hollis BW, Wagner CL. Clinical review: the role of the parent compound vitamin D with respect to metabolism and function: why clinical dose intervals can affect clinical outcomes. J Clin Endocrinol Metab 2013:98:4619-28.

6 Hollis BW, Wagner CL, Drezner MK, et al. Circulating vitamin D3 and 25-hydroxyvitamin D in humans: an important tool to define adequate nutritional vitamin D status. J Steroid Biochem Mol Biol 2007;103:631-4.

7 Luxwolda MF, Kuipers RS, Kema IP, et al. Traditionally living populations in East Africa have a mean serum 25-hydroxyvitamin $D$ concentration of 115 nmol/l. Br J Nutr 2012;108:1557-61.

8 Luxwolda MF, Kuipers RS, Kema IP, et al. Vitamin D status indicators in indigenous populations in East Africa. Eur J Nutr 2013;52:1115-25.
9 Martineau AR, Hanifa Y, Witt KD, et al. Double-blind randomised controlled trial of vitamin D3 supplementation for the prevention of acute respiratory infection in older adults and their carers (ViDiFlu). Thorax 2015;70:953-60.

10 Vieth R. How to optimize vitamin D supplementation to prevent cancer, based on cellular adaptation and hydroxylase enzymology. Anticancer Res 2009;29:3675-84.

11 Murdoch DR, Slow S, Chambers ST, et al. Effect of vitamin D3 supplementation on upper respiratory tract infections in healthy adults: the VIDARIA randomized controlled trial. JAMA 2012;308:1333-9.

12 Martineau AR, James WY, Hooper RLM et al. Vitamin D3 supplementation in patients with chronic obstructive pulmonary disease (ViDiCO): a multicentre, double-blind, randomised controlled trial. The Lancet Respiratory Medicine 2015;3:120-30.

13 Martineau AR, MacLaughlin BD, Hooper RL, et al. Double blind randomised placebo-controlled trial of bolus-dose vitamin D3 supplementation in adults with asthma (ViDiAs). Thorax 2015;70: 451-7.

14 Camargo CA, Ganmaa D, Frazier AL, et al. Randomized Trial of vitamin D supplementation and risk of acute respiratory infection in Mongolia. Pediatrics 2012;130:e561-7.

15 Laaksi I, Ruohola JP, Mattila V, et al. Vitamin D supplementation for the prevention of acute respiratory tract infection: a randomised, double blinded trial among young Finnish men. J Infect Dis 2010;202:809-14. 